\title{
Intravenous injection of post-hemorrhagic shock mesenteric lymph induces multiple organ injury in rats
}

\author{
YIFENG ZHAO $^{1,2}$, LIMIN ZHANG ${ }^{1}$, RUI HAN ${ }^{1}$, YONGHUA SI $^{1,3}$ and ZIGANG ZHAO ${ }^{1}$ \\ ${ }^{1}$ Institute of Microcirculation, Hebei North University; ${ }^{2}$ Department of Oncological Surgery, \\ The Affiliated Hospital of Hebei North University, Zhangjiakou, Hebei 075000; ${ }^{3}$ Department of Pediatrics, \\ Cangzhou City People's Hospital, Cangzhou, Hebei 061000, P.R. China
}

Received February 12, 2018; Accepted November 14, 2018

DOI: $10.3892 /$ etm.2018.7048

\begin{abstract}
Post-hemorrhagic shock mesenteric lymph (PHSML) has an important role in the multiple organ injuries caused by severe shock. The current study investigated whether intravenous injection of PHSML induces organ injury in normal rats. Following the establishment of hemorrhagic shock in donor rats $(40 \pm 2 \mathrm{mmHg}, 3 \mathrm{~h})$, PHSML was drained during hypotension at 1-3 $\mathrm{h}$ and then injected to normal rats through the femoral vein within $30 \mathrm{~min}$. The mean arterial pressure (MAP) was measured, and samples were obtained for analysis of histology and biochemical indices at $2.5 \mathrm{~h}$ post-PHSML administration. PHSML administration resulted in a significant decrease in MAP at the early and late stage of the experiment. Structural damage of the lung, kidney, heart and liver was also observed, and the levels of urea, creatinine, aspartate aminotransferase, total bile acid and creatine kinase MB isoenzyme were increased in the plasma. Additionally, PHSML injection significantly increased the levels of trypsin, tumor necrosis factor- $\alpha$ (TNF- $\alpha)$, intercellular adhesion molecule-1 and receptor of advanced glycation end-products in the plasma, malondialdehyde in the lung and myocardium, and TNF- $\alpha$ in the lung, kidney, myocardium and liver. Intravenous injection of PHSML induced multiple organ injury in normal rats via increases in trypsin activity, inflammatory factors and free radical production. The findings indicate that PHSML return is an important contributor to organ damage following hemorrhagic shock.
\end{abstract}

\section{Introduction}

Shock caused by acute hemorrhage is responsible for $\sim 40 \%$ of all trauma-associated fatalities $(1,2)$. It has long been recognized

Correspondence to: Professor Zigang Zhao, Institute of Microcirculation, Hebei North University, 11 Diamond South Road, Zhangjiakou, Hebei 075000, P.R. China

E-mail:zzghyl@126.com

Key words: hemorrhagic shock, mesenteric lymph, intravenous injection, multiple organ injuries that multiple organ injuries are associated with death induced by severe hemorrhagic shock (3-5). The gut is one of primary organs affected by ischemia following acute hemorrhage, and ischemic gut injury induces bacteria/endotoxin translocation that causes further remote organ injury (6). Previous studies have revealed that unique gut-derived factors carried in the mesenteric lymph, but not the portal vein, lead to acute organ injury and multiple organ dysfunction syndrome (MODS) following hemorrhagic shock (7-11). Previous studies have indicated that blockage of post-hemorrhagic shock mesenteric lymph (PHSML) return by mesenteric lymph duct ligation could alleviate the pulmonary injury, cardiac contractile dysfunction and acute kidney injury (12-15). Furthermore, PHSML intravenous infusion into naïve rats induced myocardial contractile dysfunction and decreased RBC deformability $(16,17)$. These results indicate that the return of PHSML to blood circulation is involved in the process of hemorrhagic shock-induced MODS. However, the detailed role of PHSML return in the pathogenesis of MODS remains unclear; therefore, it may be useful to investigate the association between PHSML and MODS following hemorrhagic shock. In addition, previous studies have demonstrated that the increased trypsin activity and the subsequent downstream protease cascade serve an important role in hemorrhagic shock-induced tissue injury and dysfunction besides inflammation $(18,19)$. Therefore, in the current study, the effect of intravenous injection of PHSML on trypsin activity, inflammatory factors, free radical production and multiple organ injuries in normal rats was investigated. The results revealed that PHSML has a causal role in mediating multiple organ injuries following hemorrhagic shock.

\section{Materials and methods}

Animals. Adult, male, specific pathogen-free Wistar rats $(\mathrm{n}=18$; age, 3-4 months; weight, 230-270 g) were purchased from the Animal Breeding Center of Chinese Academy of Medical Sciences (Beijing, China). Rats were housed in clear plastic cages at a temperature of $22-24^{\circ} \mathrm{C}$ and a humidity of $40-50 \%$, under a $12 \mathrm{~h}$ light/dark cycle with free access to water and food. All rats were fasted for $12 \mathrm{~h}$, but allowed free access to water, before the experiments. The animal study was approved by the Institutional Animal Use and Care Committee of Hebei North University (Zhangjiakou, China). 
Preparation of PHSML. Six rats were used to establish the hemorrhagic shock model for preparation of PHSML, as previously described $(20,21)$. Rats were anesthetized with $50 \mathrm{mg} / \mathrm{kg}$ sodium pentobarbital (Beijing Chemical Reagents Institute, Beijing, China). The femoral artery and mesenteric lymph duct catheterization were performed for hemorrhage, and mean arterial pressure (MAP) monitoring and PHSML drainage, respectively. Following an equilibrium period of $30 \mathrm{~min}$, the hemorrhage was conducted via the left femoral artery, and the MAP was maintained at a level of $40 \mathrm{mmHg}$ for $3 \mathrm{~h}$ by withdrawing or perfusing shed blood as needed for the establishment of the hemorrhagic shock model. Subsequently, the PHSML was drained from 1-3 $\mathrm{h}$ of hypotension. It should be noted that the PHSML collected from 1 rat with hemorrhagic shock was in the range of $0.15-0.25 \mathrm{ml}$; then, the PHSML was centrifuged for $5 \mathrm{~min}$ at $315 \mathrm{~g}$ at $4^{\circ} \mathrm{C}$ and stored at -75 to $-80^{\circ} \mathrm{C}$ before further experimentation. Following the collection of the PHSML, the rats were humanely sacrificed by cervical dislocation while under deep anesthetic conditions.

Intravenous injection of PHSML. The 12 rats were randomly divided into the control group and PHSML group $(n=6$ rats in each group). Following anesthetization, the femoral artery and vein were catheterized for MAP monitoring and PHSML (PHSML group) or normal saline (control group) injection, respectively, as described previously $(10,11)$. Following a stabilization period of $30 \mathrm{~min}$, cell-free supernatant fluid from PHSML samples was diluted with an equal amount of saline and injected into rats intravenously at a dose of $2 \mathrm{ml} / \mathrm{kg}$ within $30 \mathrm{~min}$. In the control group rats, the equal volume of saline was injected intravenously.

Collection and preparation of samples. At $150 \mathrm{~min}$ post-intravenous injection, blood samples were collected from the abdominal aorta and the plasma was obtained by centrifugation at $850 \mathrm{xg}$ at $0-4^{\circ} \mathrm{C}$ for $10 \mathrm{~min}$ and stored at -75 to $-80^{\circ} \mathrm{C}$ for assay of biochemical indicators, trypsin, tumor necrosis factor- $\alpha$ (TNF- $\alpha$ ), intercellular adhesion molecule-1 (ICAM-1) and receptor of advanced glycation end-products (RAGE). Following blood sample collection, the rats were sacrificed as above. Subsequently, lung, kidney, liver and heart samples were harvested and fixed. One part of each organ was fixed in $4 \%$ paraformaldehyde at $22-24^{\circ} \mathrm{C}$ for 1 week to determine morphological changes, while the remaining part of each organ was homogenized for the measurement of malondialdehyde (MDA) and TNF- $\alpha$.

Observation of history. Following $24 \mathrm{~h}$ of fixation with paraformaldehyde, the tissues were dehydrated in an alcohol gradient and embedded in paraffin. Sections $(5 \mu \mathrm{m})$ were prepared and stained with hematoxylin and eosin at room temperature for $3 \mathrm{~min}$ and $1 \mathrm{~min}$, respectively. Morphological changes in the lung, kidney, liver and myocardium were observed using a light microscope (90i; Nikon Corporation, Tokyo, Japan) and micrographs were obtained using an image collection and analysis system (Eclipse; Nikon Corporation) at a magnification of $\mathrm{x} 400$.

Measurement of biochemical indicators. To assess the renal, hepatic and myocardial function, the plasma levels of urea (Shanghai Fahrenheit Asia-Pacific Biopharmaceutical Co., Ltd., Shanghai, China; cat. no. 20101210), creatinine (Cre; Shanghai Fahrenheit Asia-Pacific Biopharmaceutical Co., Ltd.; cat. no. 10122101), aspartate aminotransferase (AST; Wako Pure Chemical Industries, Ltd., Osaka, Japan; cat. no. EH564), alanine aminotransferase (ALT; cat. no. EH567; Wako Pure Chemical Industries, Ltd.), total bile acid (TBA; cat. no. GZD10301; Neusoft Witman Biotechnology Co., Ltd., Nanjing, China), lactate dehydrogenase 1 (LDH-1; cat. no. 10091902; Zhejiang Dongsheng Diagnostic Products Co., Ltd., Wenzhou, China) and creatine kinase MB isoenzyme (CK-MB; cat. no. 20101112; Shanghai Kehua Bio-engineering Co., Ltd.) were examined using an automatic biochemical analyzer (7600-110; Hitachi, Ltd., Tokyo, Japan).

Examination of trypsin activity. Using the hydrolysis method, the trypsin activity in plasma was determined according to the manufacturer's instructions (Jiancheng Biotechnology Research Institute, Nanjing, China). One unit of trypsin activity corresponded to the amount of enzyme that produced an increased absorbance of 0.003 per min at $253 \mathrm{~nm}, \mathrm{pH} 8.0$ and $37^{\circ} \mathrm{C}$.

ELISA. To determine the changes in ICAM-1, RAGE and TNF- $\alpha$ in plasma following the PHSML injection, rat-specific ELISA kits were used according to the manufacturer's recommendations. The following antibodies were purchased from R\&D Systems (Minneapolis, MN, USA): ICAM-1 (cat. no. MAB5832-100; 1:250), RAGE (cat. no. AF1616; $1: 1,000)$ and TNF- $\alpha$ (cat. no. MAB510-100; 1:250), and ELISA kits were prepared by Jiangsu Hope, Inc. (Zhenjiang, China), while the catalogue numbers were 10632R, 10433R and $10775 \mathrm{R}$, respectively. The concentration of each examined protein was calculated by comparing the optical density to that of the standard curve.

The level of TNF- $\alpha$ in tissue was measured using the same method. The protein content in homogenates was quantified by the Coomassie brilliant blue colorimetric method, and values were normalized to the protein levels.

Examination of MDA. The MDA in tissue homogenates was measured using a modified thiobarbituric acid (TBA) micro-determination assay according to the instructions provided by the manufacturer (Jiancheng Biotechnology Research Institute, Nanjing, China). Briefly, tissue homogenate $(0.1 \mathrm{ml})$ was mixed with $0.1 \mathrm{ml}$ of dehydrated alcohol, $0.1 \mathrm{ml}$ TBA and $4.0 \mathrm{ml}$ of developer. Following incubation in a water bath at $95^{\circ} \mathrm{C}$ for $40 \mathrm{~min}$, the samples were cooled in running water and then centrifuged at $1,200 \mathrm{x} g$ at room temperature for $10 \mathrm{~min}$. The absorbance of the resulting supernatant at $532 \mathrm{~nm}$ was measured and the MDA level was presented as $\mathrm{nmol} / \mathrm{mg}$ protein.

Statistical analysis. Data are collected and presented as the mean \pm standard deviation. Statistical analysis was performed using SPSS 16.0 for Windows (SPSS Inc., Chicago, IL, USA). Differences between the two groups were analyzed using an independent sample Student's t-test. $\mathrm{P}<0.05$ was considered to indicate a statistically significant difference. 


\section{Results}

Effect of PHSML on MAP. Intravenous injection of saline did not result in a significant change in the MAP in rats (105 to $112 \mathrm{mmHg}, \mathrm{P}>0.05)$. By contrast, intravenous injection with PHSML induced a significant decrease in the MAP during the injection period $(\mathrm{P}<0.05)$. This decreased MAP gradually returned to a normal level. At $90 \mathrm{~min}$, the MAP started declining again, and reached the minimum at 165-180 min compared with the control rats $(\mathrm{P}<0.05$; Fig. 1$)$.

Effect of intravenous injection on the morphology of the lung, kidney, myocardium and liver. Rats that received saline injection had normal alveolar architecture, with thin walls covered by alveolar epithelial cells (Fig. 2A). By contrast, the rats that received the PHSML injection had broadening alveolar septum with inflammatory cell infiltration.

In the kidney of the control group rats, there was normal architecture in the renal glomerulus and tubules, and there were clear and distinctive proximal and distal convoluted tubules (Fig. 2B). By contrast, the rats that received PHSML administration exhibited epithelial cells with swelling in the tubules, and there was a small amount of protein deposition in the Bowman's capsule.

Imaging of myocardial sections revealed that the rats in the control group had normal myocardial fiber bundles and uniform myocardial cells with central nuclei and clear nuclear membranes, whereas the PHSML administration induced the disorganization of myocardial fibers (Fig. 2C).

In the liver sections of control mice, the hepatocytes were properly organized, with round central nuclei and clear nuclear membrane (Fig. 2D). In the rats that received the PHSML injection, the hepatocytes were slightly disorganized and exhibited edema.

Effect of PHSML on the biochemical markers in plasma. Urea and Cre, AST and TBA, and CK-MB are markers of renal function, hepatocyte necrosis and function, and cardiomyocyte injury, respectively (22-24). In the PHSML group, these indices were significantly increased compared with the control group $(\mathrm{P}<0.05)$. However, there was no statistical difference in the level of ALT and LDH-1 between the control and PHSML groups ( $\mathrm{P}>0.05$; Fig. 3$)$.

Effect of PHSML on trypsin, ICAM-1, RAGE and TNF- $\alpha$ in plasma. The activity of trypsin, and ICAM-1, RAGE and TNF- $\alpha$ levels in plasma samples from the PHSML group (372.00 $\pm 79.77 \mathrm{U} / \mathrm{ml}, 24.57 \pm 2.43 \mathrm{ng} / 1,7.81 \pm 2.86 \mathrm{mg} / \mathrm{l}$ and $598.16 \pm 131.38 \mathrm{ng} / \mathrm{l}$, respectively) were significantly increased compared with the control group $(155.00 \pm 50.62 \mathrm{U} / \mathrm{ml}$, $18.58 \pm 2.08 \mathrm{ng} / \mathrm{l}, 5.10 \pm 2.02 \mathrm{mg} / \mathrm{l}$ and $324.28 \pm 78.22 \mathrm{ng} / \mathrm{l} ; \mathrm{P}<0.05$; Fig. 4).

Effect of PHSML injection on the MDA level in tissues. PHSML administration resulted in a significant increase in the MDA content in pulmonary and myocardial tissue homogenates compared with that in the control group ( $\mathrm{P}<0.05$; Fig. 5$)$. However, there was no statistical difference in the MDA level of hepatic and renal tissue homogenates between the control and PHSML groups $(\mathrm{P}>0.05)$.

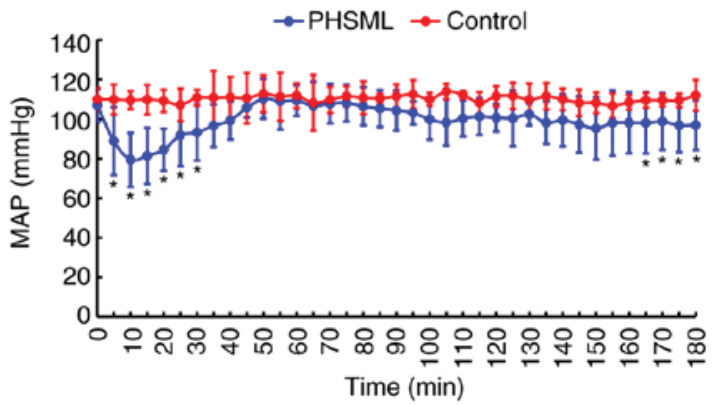

Figure 1. Intravenous injection of PHSML decreases the MAP of the normal rats. Data are presented as the mean \pm standard deviation $(n=6)$. ${ }^{*} \mathrm{P}<0.05$ vs. control group. MAP, mean arterial pressure; PHSML, post-hemorrhagic shocked mesenteric lymph.

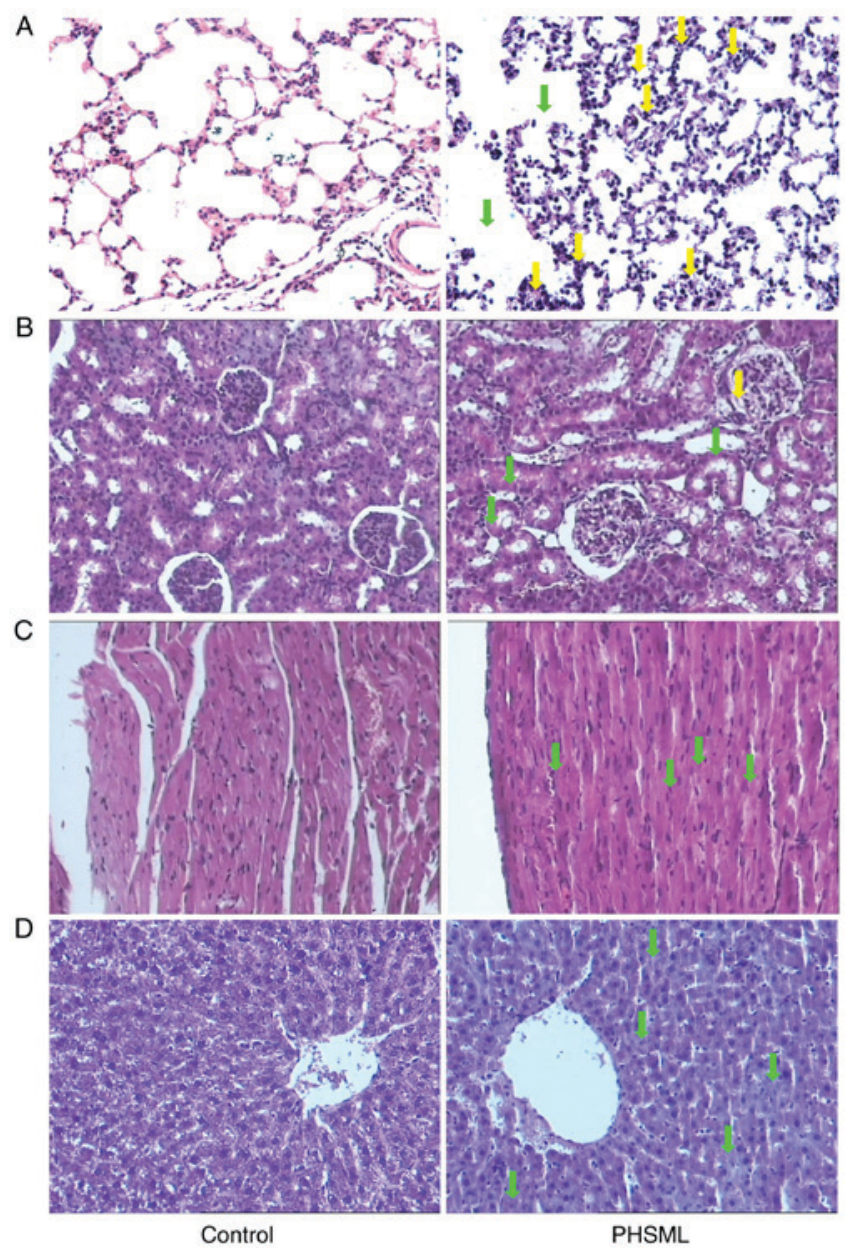

Figure 2. Intravenous injection of PHSML induces histological damage of lung, kidney, myocardium and liver in normal rats (hematoxylin and eosin staining; magnification, x400). (A) Lung, green arrows indicate broadening alveolar septum and yellow arrows indicate inflammatory cell infiltration. (B) Kidney, green arrows indicate epithelial cells cloudy swelling, yellow arrows indicate small amount of protein deposition. (C) Myocardium, green arrows indicate disorganized myocardial fibers. (D) Liver, green arrows indicate edema in hepatocytes. PHSML, post-hemorrhagic shocked mesenteric lymph.

Effect of intravenous PHSML injection on the TNF- $\alpha$ level in tissues. The results indicated that TNF- $\alpha$ levels were significantly higher in lung, kidney, myocardium and liver samples from the PHSML group compared with the control group $(\mathrm{P}<0.05$; Fig. 6). 

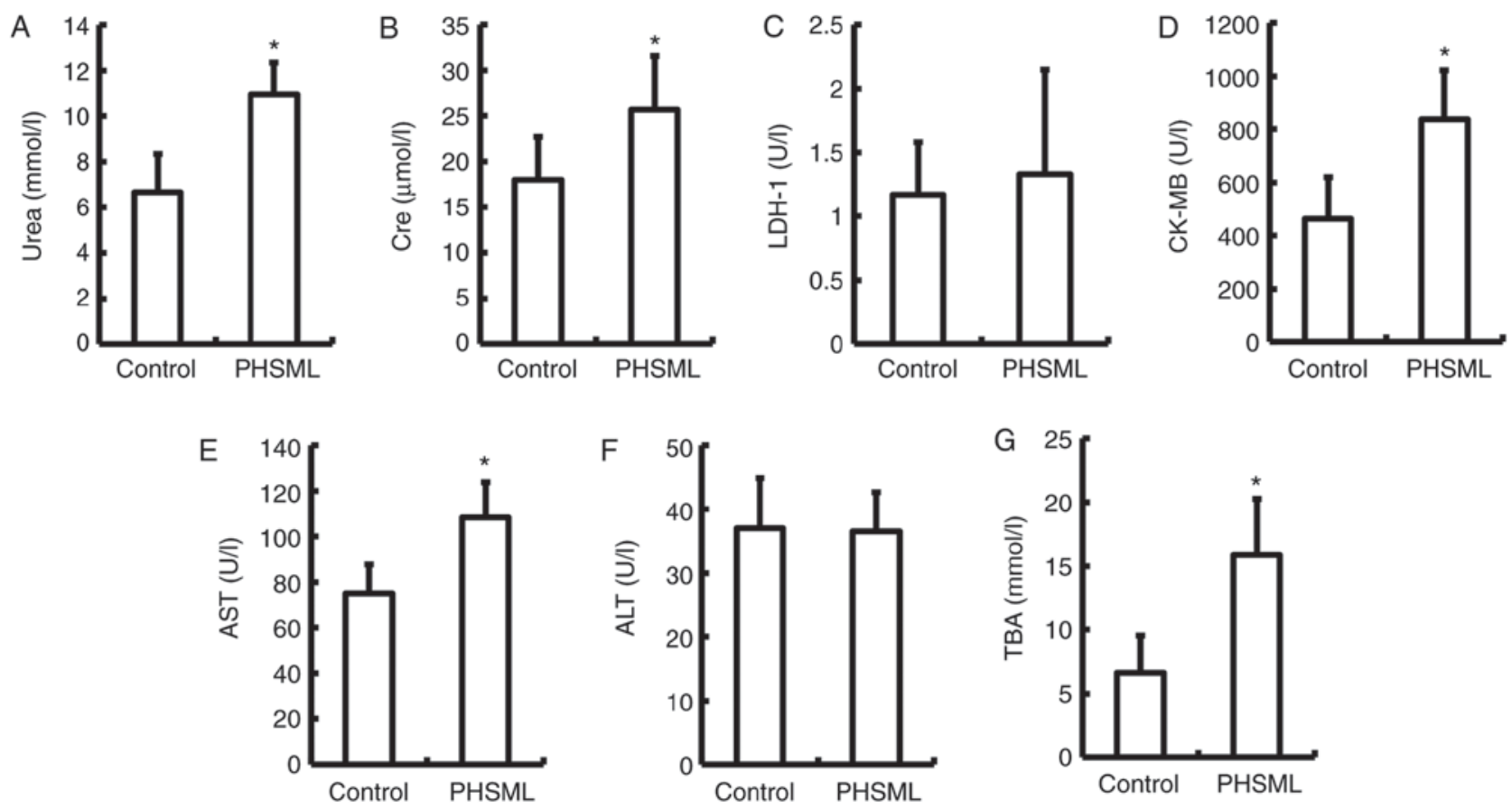

Figure 3. Effect of PHSML injection on biochemical indices in plasma of normal rats. Data are presented as the mean \pm standard deviation ( $\mathrm{n}=6$ ). (A) Lung; (B) kidney; (C) myocardium; and (D) liver. (A) Urea; (B) Cre; (C) LDH-1; (D) CK-MB; (E) AST; (F) ALT; and (G) TBA. "P<0.05 vs. control group. PHSML, post-hemorrhagic shocked mesenteric lymph; Cre, creatinine; LDH-1, lactate dehydrogenase 1; CK-MB, creatine kinase MB isoenzyme; AST, aspartate aminotransferase; ALT, alanine aminotransferase; TBA, total bile acid
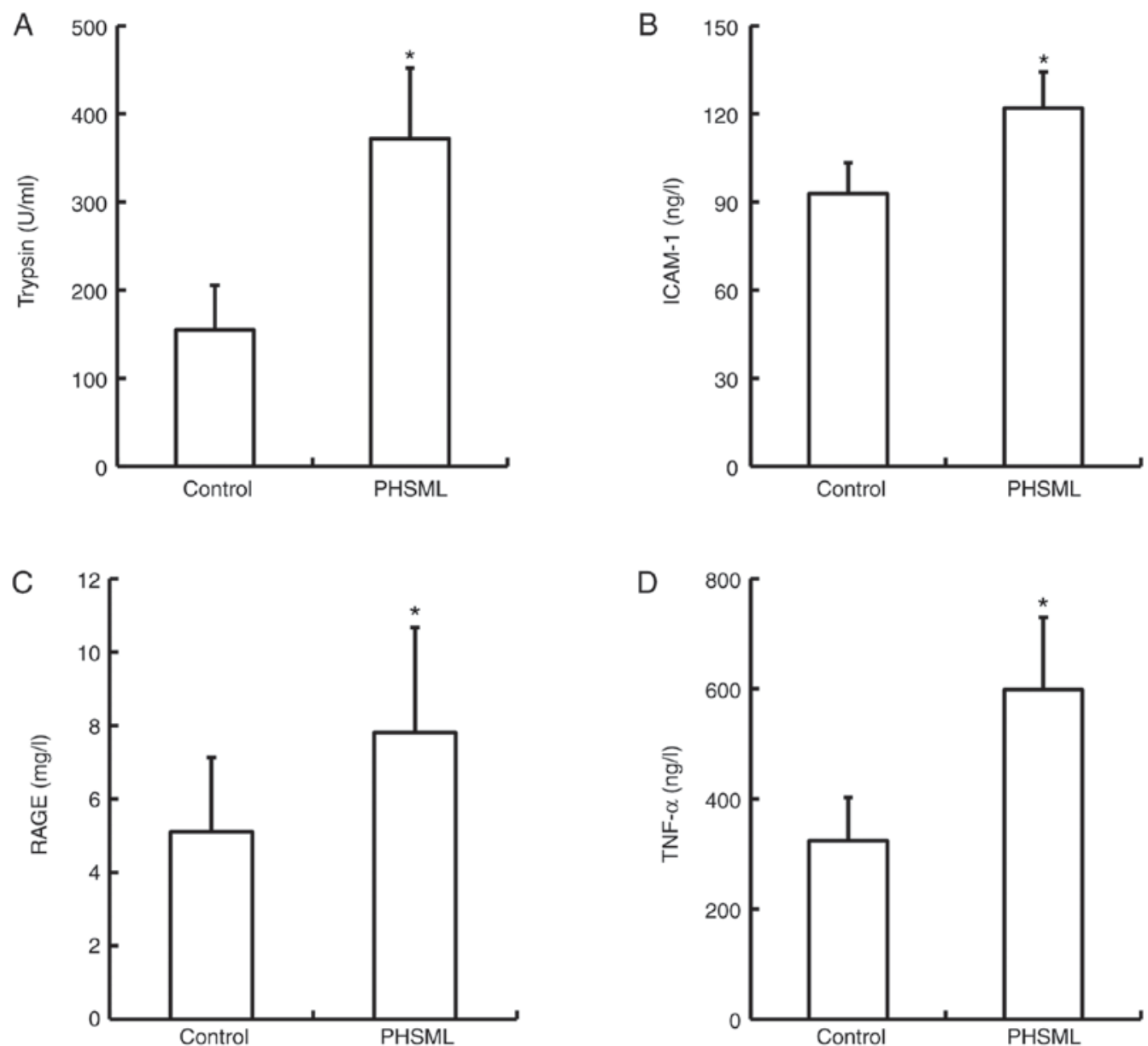

Figure 4. Intravenous injection of PHSML increases the levels of trypsin, ICAM-1, RAGE, and TNF- $\alpha$ in plasma of the normal rats. Data are presented as the mean \pm standard deviation ( $\mathrm{n}=6$ ). (A) Trypsin; (B) ICAM-1; (C) RAGE; and (D) TNF- $\alpha$. "P<0.05 vs. control group. PHSML, post-hemorrhagic shocked mesenteric lymph; ICAM-1, intercellular adhesion molecule-1; RAGE, receptor of advanced glycation end-products; TNF- $\alpha$, tumor necrosis factor- $\alpha$. 


\section{Discussion}

Based on the previous studies (7-11) implicating gut-derived factors carried in the mesenteric lymph as contributing factors to tissue injury and dysfunction caused by hemorrhagic shock, PHSML was drained from rats with hemorrhagic shock and injected into normal rats in the current study. The injected animals exhibited a phased decrease in blood pressure and damage to the lung, kidney, heart and liver. The results confirm that the PHSML is an important contributor to organ injuries following hemorrhagic shock.

In the current study, PHSML injection induced a significant decrease in MAP at the early and late stage during the experiment. Thus, the pattern is similar to the effects observed following LPS administration $(25,26)$. Similar to LPS administration, PHSML injection has been revealed to induce damage to red blood cells, which contributes to decreased microcirculatory blood flow and organ hypoperfusion (27). Intravenous infusion of PHSML was also reported cause myocardial contractile dysfunction and diminish the left ventricular developed pressure (LVDP) and the maximal rate of LVDP rise and fall $[ \pm \mathrm{dP} / \mathrm{dt}(\max )]$ in a previous study (16). This indicated that hypotension at the early and late stage post-PHSML injection may be caused by the adverse effects of PHSML on blood flow and myocardial function.

The effects of PHSML injection on tissue morphology, and biochemical indices that reflect organ function or cell injury were determined in the current study. Intravenous injection of PHSML induced structural damage in the lung, kidney, myocardium and liver, including inflammatory cell infiltration in the alveolar septum, protein deposition in the Bowman's capsule, disorganization of myocardial fibers and slight edema in hepatocytes. In addition, PHSML administration resulted in significant increases in urea, Cre, AST, TBA and CK-MB in the plasma, which further confirmed the toxic effect of PHSML at the organ level.

Trypsin, a proteolysis enzyme, is released from damaged cells, which causes excessive protein catabolism and exacerbates cell injury (28). In the current study, the trypsin activity in plasma was significantly increased by PHSML injection, suggesting that the toxic components from PHSML caused cell injury resulting in increased trypsin release. In addition, it is possible that there was a high concentration of trypsin in the PHSML itself, which exacerbated organ injury in a positive feedback manner.

RAGE, a member the immunoglobulin super-family, has a pivotal role in binding advanced glycation end-products (AGEs). The binding of RAGE with AGEs induces inflammatory responses that can result in cell injury or tissue damage. Therefore, RAGE can be used as a marker of inflammation and injury (29). Previous studies have indicated that the activation of RAGE-dependent signaling is involved in gut mucosal barrier dysfunction, and the excessive inflammation but occurs following hemorrhagic shock and resuscitation (30). RAGE signaling also promotes the mobilization of hematopoietic progenitor cells from bone marrow (31). In the current study, RAGE and TNF- $\alpha$ were significantly increased following administration of PHSML to normal rats. These results indicate the excessive inflammation derived from increased RAGE is involved in the process of tissue injury following PHSML injection.

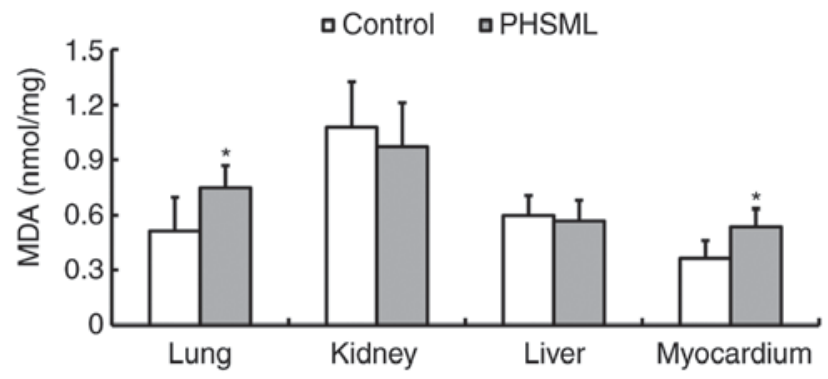

Figure 5. Effect of PHSML intravenous injection on the MDA content in tissue homogenate of normal rats. Data are presented as the mean \pm standard deviation $(n=6)$. ${ }^{*} \mathrm{P}<0.05$ vs. control group. PHSML, post-hemorrhagic shocked mesenteric lymph; MDA, malondialdehyde.

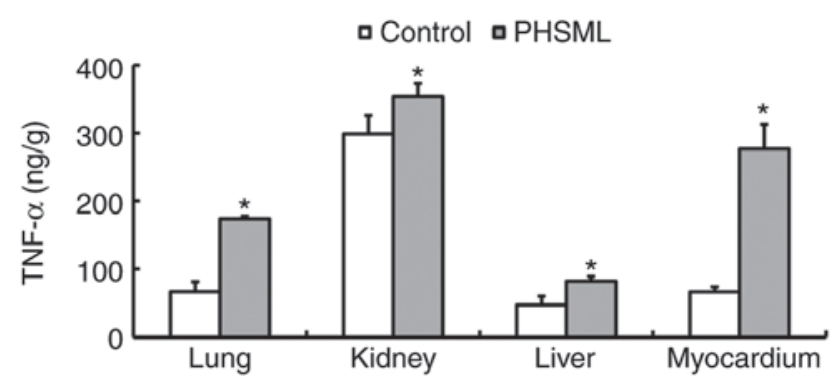

Figure 6. Intravenous injection of PHSML increases the contents of TNF-O in tissue homogenate of normal rats. Data are presented as the mean \pm standard deviation $(n=6)$. ${ }^{*} \mathrm{P}<0.05$ vs. control group. PHSML, post-hemorrhagic shocked mesenteric lymph; TNF- $\alpha$, tumor necrosis factor- $\alpha$.

During hemorrhagic shock, increased levels of ICAM-1 induce $\mathrm{s}$ adhesion and activation of inflammatory cells, which is a key indicator of uncontrolled inflammatory responses and organ dysfunction (32). Interference with ICAM-1 may be beneficial for regaining and/or maintaining the balance of inflammation and organ function (32-34). In the current study, ICAM-1 was increased in plasma, and TNF- $\alpha$ was increased in plasma, lung, kidney, liver and myocardium samples following PHSML injection, suggesting that tissue injury was caused by ICAM-1-induced inflammation.

The excessive production of endogenous free radicals, such as MDA and reactive oxygen species, can destroy the structural integrity of cell membranes and organelles, thus activating a cascade of free radical injury through reactions with unsaturated fatty acid located in the cell membrane, producing lipid peroxides $(35,36)$. In the current study, PHSML administration resulted in an increase in the MDA level in the lung and myocardium, indicating that the pulmonary and myocardial injuries were associated with free radical. However, there were no statistical differences in the MDA contents in the kidney and hepatic tissue samples, which may be associated with the short observation time used in the current study.

It should be noted that there are several limitations in the current study. For example, multiple intracellular signaling pathways, including the mitogen-activated protein kinase pathway and I $\kappa$ B kinase-nuclear factor- $\kappa$ B pathway, coordinate the induction of inflammatory mediators and induce inflammation during hemorrhagic shock $(3,37)$. However, in the current study, only the adverse effects of PHSML on trypsin activity 
and inflammatory mediator levels were examined; therefore, whether these signaling pathways are involved in the mechanism of the PHSML injection-induced inflammatory response requires further investigation. Additionally, given the role of white blood cells (WBC) in supporting systemic inflammation, whether PHSML injection induces an increase in WBC counts in peripheral blood should be investigated in the future.

In addition, the activity of trypsin and the levels of ICAM-1, RAGE and TNF- $\alpha$ were not measured in the lymph obtained from hemorrhagic shock rats. These factors may induce the adverse effects observed in the current study if there are high concentrations in the lymph. However, the amount of PHSML injected to recipient rats was only $0.23-0.27 \mathrm{ml}$ (according the dose of $1 \mathrm{ml} / \mathrm{kg}$ ), which was much less than the whole rat blood volume of 17.7-20.8 $\mathrm{ml}(\sim 1 / 13$ body weight); thus, it is likely that the changes in serum mediators in recipient rats arise mainly from PHSML stimulation, rather than the factors in PHSML itself from the donor rats.

In conclusion, the findings of current study demonstrated that the intravenous injection of PHSML induces organ injury in normal rats, and that this adverse effect is associated with increased trypsin activity, inflammatory mediators and free radicals. Combined with the previous study demonstrating that PHSML drainage decreases the levels of trypsin activity in the plasma and ICAM-1, RAGE, TNF- $\alpha$ and MDA in renal tissue (38), these findings further elucidate the mechanism underlying multiple organ injuries induced by the return of PHSML following severe hemorrhagic shock.

\section{Acknowledgements}

The authors would like to thank Professor Chun-yu Niu (Institute of Microcirculation, Hebei North University, Zhangjiakou, Hebei, China) for designing the current study and obtaining funding.

\section{Funding}

The current study was supported by the National Natural Science Foundation of China (grant no. 30370561) and the Doctoral Scientific Fund Project of Hebei North University (grant no. 201710).

\section{Availability of data and materials}

The datasets used and/or analyzed during the current study are available from the corresponding author on reasonable request.

\section{Authors' contributions}

YZ, LZ, RH and YS acquired the data. YZ also wrote the manuscript. $\mathrm{ZZ}$ was involved in the conception and design of the study, data analysis and interpretation, and critically revised the manuscript.

\section{Ethics approval and consent to participate}

The present study was approved by the Institutional Animal Use and Care Committee of Hebei North University (Zhangjiakou, China).

\section{Patient consent for publication}

Not applicable.

\section{Competing interests}

The authors declare that they have no competing interests.

\section{References}

1. Sauaia A, Moore FA, Moore EE, Moser KS, Brennan R, Read RA and Pons PT: Epidemiology of trauma deaths: A reassessment. J Trauma 38: 185-193, 1995.

2. Huang Y, Ratz PH, Miner AS, Locke VA, Chen G, Chen Y and Barbee RW: AICAR administration attenuates hemorrhagic hyperglycemia and lowers oxygen debt in anesthetized male rabbits. Front Physiol 8: 692, 2017.

3. Korff S, Loughran P, Cai C, Lee YS, Scott M and Billiar TR: Eritoran attenuates tissue damage and inflammation in hemorrhagic shock/trauma. J Surg Res 184: e17-e25, 2013.

4. Douzinas EE: Hemorrhagic shock resuscitation: A critical issue on the development of posttraumatic multiple organ failure. Crit Care Med 40: 1348-1349, 2012.

5. Hildebrand F, Andruszkow H, Huber-Lang M, Pape HC and van Griensven M: Combined hemorrhage/trauma models in pigs-current state and future perspectives. Shock 40: 247-273, 2013.

6. Tarras SL, Diebel LN, Liberati DM and Ginnebaugh K: Pharmacologic stimulation of the nicotinic anti-inflammatory pathway modulates gut and lung injury after hypoxia-reoxygenation injury. Surgery 154: 841-848, 2013.

7. Deitch EA, Xu D and Kaise VL: Role of the gut in the development of injury- and shock induced SIRS and MODS: The gut-lymph hypothesis, a review. Front Biosci 11: 520-528, 2006.

8. Deitch EA: Gut-origin sepsis: Evolution of a concept. Surgeon 10: 350-356, 2012.

9. Deitch EA: Gut lymph and lymphatics: A source of factors leading to organ injury and dysfunction. Ann N Y Acad Sci 1207 (Suppl 1): E103-E111, 2010.

10. Cai B, Deitch EA and Ulloa L: Novel insights for systemic inflammation in sepsis and hemorrhage. Mediators Inflamm 2010: 642462, 2010.

11. Fanous MY, Phillips AJ and Windsor JA: Mesenteric lymph: The bridge to future management of critical illness. JOP 8: 374-399, 2007.

12. Sambol JT, Xu DZ, Adams CA, Magnotti LJ and Deitch EA: Mesenteric lymph duct ligation provides long term protection against hemorrhagic shock-induced lung injury. Shock 14: 416-420, 2000.

13. Deitch EA, Adams C, Lu Q and Xu DZ: A time course study of the protective effect of mesenteric lymph duct ligation on hemorrhagic shock-induced pulmonary injury and the toxic effects of lymph from shocked rats on endothelial cell monolayer permeability. Surgery 129: 39-47, 2001.

14. Sambol JT, Lee MA, Caputo FJ, Kawai K, Badami C, Kawai T, Deitch EA and Yatani A: Mesenteric lymph duct ligation prevents trauma/hemorrhage shock-induced cardiac contractile dysfunction. J Appl Physiol (1985) 106: 57-65, 2009.

15. Niu CY, Zhao ZG, Ye YL, Hou YL and Zhang YP: Mesenteric lymph duct ligation against renal injury in rats after hemorrhagic shock. Ren Fail 32: 584-591, 2010.

16. Sambol JT, Lee MA, Jiang M, Dosi G, Dong W, Deitch EA and Yatani A: Mesenteric lymph from rats with trauma-hemorrhagic shock causes abnormal cardiac myocyte function and induces myocardial contractile dysfunction. J Appl Physiol (1985) 111: 799-807, 2011.

17. Condon M, Senthil M, Xu DZ, Mason L, Sheth SU, Spolarics Z, Feketova E, Machiedo GW and Deitch EA: Intravenous injection of mesenteric lymph produced during hemorrhagic shock decreases RBC deformability in the rat. J Trauma 70: 489-495, 2011.

18. Rao G, Yadav VR, Awasthi S, Roberts PR and Awasthi V: Effect of liposome-encapsulated hemoglobin resuscitation on proteostasis in small intestinal epithelium after hemorrhagic shock. Am J Physiol Gastrointest Liver Physiol 311: G180-G191, 2016. 
19. Diebel ME, Diebel LN and Liberati DM: Tranexamic acid and the gut barrier: Protection by inhibition of trypsin uptake and activation of downstream intestinal proteases. Am J Surg 213: 489-493, 2017.

20. Zhao ZG, Niu CY, Wei YL, Zhang YP, Si YH and Zhang J: Mesenteric lymph return is an important contributor to vascular hyporeactivity and calcium desensitization after hemorrhagic shock. Shock 38: 186-195, 2012.

21. Zhao Z, Si Y, Zhang Y, Du S, Zhang L and Niu C: Postshock mesenteric lymph drainage ameliorates vascular reactivity and calcium sensitivity through RhoA. J Surg Res 186: 304-309, 2014.

22. Egli-Spichtig D, Zhang MYH and Perwad F: Fibroblast growth factor 23 expression is increased in multiple organs in mice with folic acid-induced acute kidney injury. Front Physiol 9: 1494, 2018.

23. Zinkhan EK, Yu B and Schlegel A: Prenatal exposure to a maternal high fat diet increases hepatic cholesterol accumulation in intrauterine growth restricted rats in part through microRNA-122 inhibition of Cyp7a1. Front Physiol 9: 645, 2018.

24. Chen H, Liu S, Liu X, Yang J, Wang F, Cong X and Chen X: Lysophosphatidic acid pretreatment attenuates myocardial ischemia/reperfusion injury in the immature hearts of rats. Front Physiol 8: 153, 2017.

25. Mederle K, Schweda F, Kattler V, Doblinger E, Miyata K, Höcherl K, Oike Y and Castrop H: The angiotensin II AT1 receptor-associated protein Arap1 is involved in sepsis-induced hypotension. Crit Care 17: R130, 2013.

26. Piechota-Polańczyk A and Gorąca A: Influence of specific endothelin-1 receptor blockers on hemodynamic parameters and antioxidant status of plasma in LPS-induced endotoxemia. Pharmacol Rep 64: 1434-1441, 2012.

27. Machiedo GW, Zaets SB, Berezina TL, Xu DZ, Feketova E, Spolarics Z and Deitch EA: Trauma-hemorrhagic shock-induced red blood cell damage leads to decreased microcirculatory blood flow. Crit Care Med 37: 1000-1010, 2009.

28. Thrower EC, Gorelick FS and Husain SZ: Molecular and cellular mechanisms of pancreatic injury. Curr Opin Gastroenterol 26 : 484-489, 2010
29. Uchida T, Shirasawa M, Ware LB, Kojima K, Hata Y, Makita K, Mednick G, Matthay ZA and Matthay MA: Receptor for advanced glycation end-products is a marker of type I cell injury in acute lung injury. Am J Respir Crit Care Med 173: 1008-1015, 2006.

30. Raman KG, Sappington PL, Yang R, Levy RM, Prince JM, Liu S, Watkins SK, Schmidt AM, Billiar TR and Fink MP: The role of RAGE in the pathogenesis of intestinal barrier dysfunction after hemorrhagic shock. Am J Physiol Gastrointest Liver Physiol 291: G556-G565, 2006

31. Xiang M, Yuan Y, Fan L, Li Y, Li A, Yin L, Scott MJ, Xiao G, Billiar TR, Wilson MA and Fan J: Role of macrophages in mobilization of hematopoietic progenitor cells from bone marrow after hemorrhagic shock. Shock 37: 518-523, 2012.

32. Li R, Zijlstra JG, Kamps JA, van Meurs M and Molema G: Abrupt reflow enhances cytokine Induced pro-inflammatory activation of endothelial cells during simulated shock and resuscitation. Shock 42: 356-364, 2014.

33. Zhao L, Luo L, Chen J, Xiao J, Jia W and Xiao Y: Utilization of extracorporeal membrane oxygenation alleviates intestinal ischemia-reperfusion injury in prolonged hemorrhagic shock animal model. Cell Biochem Biophys 70: 1733-1740, 2014.

34. Liu HZ, Liu ZL, Zhao SP, Sun CZ and Yang MS: Protective mechanism of Panax notoginseng Saponins on rat hemorrhagic shock model in recovery stage. Cell Biochem Biophys 70: 1719-1724, 2014

35. Getoff N: Vitamin C: Electron emission, free radicals and biological versatility. In Vivo 27: 565-570, 2013.

36. Bencini A, Failli P, Valtancoli B and Bani D: Low molecular weight compounds with transition metals as free radical scavengers and novel therapeutic agents. Cardiovasc Hematol Agents Med Chem 8: 128-146, 2010.

37. Kochanek AR, Fukudome EY, Li Y, Smith EJ, Liu B, Velmahos GC, de Moya M, King D and Alam HB: Histone deacetylase inhibitor treatment attenuates MAP kinase pathway activation and pulmonary inflammation following hemorrhagic shock in a rodent model. J Surg Res 176: 185-194, 2012.

38. Zhao ZG, Zhu HX, Zhang LM, Zhang YP and Niu CY: Mesenteric lymph drainage alleviates acute kidney injury induced by hemorrhagic shock without resuscitation. ScientificWorldJournal 2014: 720836, 2014. 